\title{
ENVIRONMENTAL SURROUNDING AND PERCEPTION OF SPEECH
}

\author{
Olga D. VOLCHEK
}

\begin{abstract}
A longitudinal experiment with 26 respondents was conducted to study emotional and color images of 12 men names and 6 vowels. The collected data was studied in association with environmental conditions: the time of the day, local and space weather indices. Most of the studied indices showed significant and valid changes related to the time of the day at $p \leq 0.05 \div 0.001$. Multiple correlations were revealed for the studied indices and environmental parameters at $p \leq 0.05 \div 0.001$.
\end{abstract}

Keywords: time of day, perception of speech, personal name, image of name, value shift phenomenon, environmental conditions

\section{INTRODUCTION}

The wholesome images of the world transmitted via speech and music reflect the global characteristics of physical environment, including temperature, atmospheric parameters, gravity, magnetic and electromagnetic fields [1]. It was discovered earlier that names associate with a certain color, emotional and personal images. Some traits of an image of the name can change with time. The longer the period of the time analyzed, the more significant are the changes. It was also shown that the evolution of the human audial system corresponds with changes in the environmental surrounding [2].

A.P. Zhuravlev discovered the value shift phenomenon: the words with a positive semantic meaning associate with more negative emotional images, and vice versa. It can lead to the less frequent usage of a word, as well as of a personal name, or even to its disappearance in speech. In the case of a personal name, the names with a positive meaning but a negative value shift of their 
emotional image are gradually taken from practical usage [5]. The studies by T. M. Rogozhnikova and her students revealed the dynamic functioning of words and texts in the individual mind [3].

We should also mention that many religions have their praying calendars prescribing certain prays for certain days, as well as the prays associated with the certain time of the day. The above-said inspired me to study the perception of speech in relation to main parameters of environmental surrounding. Emotional and color images of personal names and vowels were taken for an experimental model. The original hypothesis was that variations in environmental surrounding influence the perception of speech and the value shift phenomenon, which consequently puts an impact on the evolution of speech and the so-called naming trend.

\section{METHODS AND MATERIALS}

The resources of web science were engaged: once a week (in some weeks more than once) volunteer respondents were filling out the received by email form on the designated day but at any convenient for them time. The total number of respondents was 26: 6 men and 20 women. 9 persons had musical education. In the form they were asked to estimate 12 men names and 6 vowels of Russian language A [a], E [e], И [i], O [o], У [u], Ы [a specific Russian vowel]. The positions of names and vowels in the list were regularly and randomly changed. The respondents were given the following directions: "Judging by the way a name or vowel sounds, give the indicated parameter scores from 0 to 5 , according to your opinion. Also, write one or two associating colors for each name and each vowel. Try not to think too long but mark the first values that come to your mind. It can be at random but must be in silence".

The collected data was grouped by the experimental days, by the time of the day, by respondents and compared with a range of the main local and global environmental parameters. The local environmental parameters included the time of the day, weather conditions in Saint Petersburg (air temperature, $\mathrm{C}^{\circ}$; atmospheric pressure, $\mathrm{mm} \mathrm{Hg}$, wind speed, $\mathrm{m} / \mathrm{s}$; humidity, \%; precipitation, $\mathrm{mm}$ ) and the duration of daylight (DD), min. The global parameters we used were the lunar phase, the disturbed or quiet geomagnetic field (GMF), the number of solar spots W; the geomagnetic activity index Dst; the magnetic field of the Sun as a star SMF; the gravity index G, which is a long-period component 
of the potential of the tidal power of the Moon and the Sun. The values of the index G were calculated by L.N. Petrova, $\mathrm{PhD}$ in Physics and Math Science, and I would like to express my deep gratitude for her help.

The experiment lasted from 1 February, 2013 to 7 June, 2013, but after 5 April the number of respondents was decreased to 14 persons. The mathematic analysis of the data was performed with Statistica 6.0 software, engaging t-criterion, Fisher criterion $\boldsymbol{\varphi}^{*}$ and correlation analysis [7].

\section{RESULTS AND DISCUSSION}

For the data from 1 February to 5 April the averaged values for names and vowels at different times of day were calculated. Sample sizes for names were 726 (morning), 924 (afternoon), 1,006 (evening), 784 (night); for vowels - 61 (morning), 77 (afternoon), 84 (evening), 66 (night). All the indices of emotional and color image for names and vowels varied depending on the time of the day.

Figure 1 demonstrates the variations in the values of the index Good depending on the time of the day. This index can be taken as integrated. There are significant and valid differences between the lowest and the highest values extremes - for each name studied. The highest values of the indices Melodicism and Good in our study belong to the name Alexandr, which corresponds with the notices by P.A. Florenskiy [8].

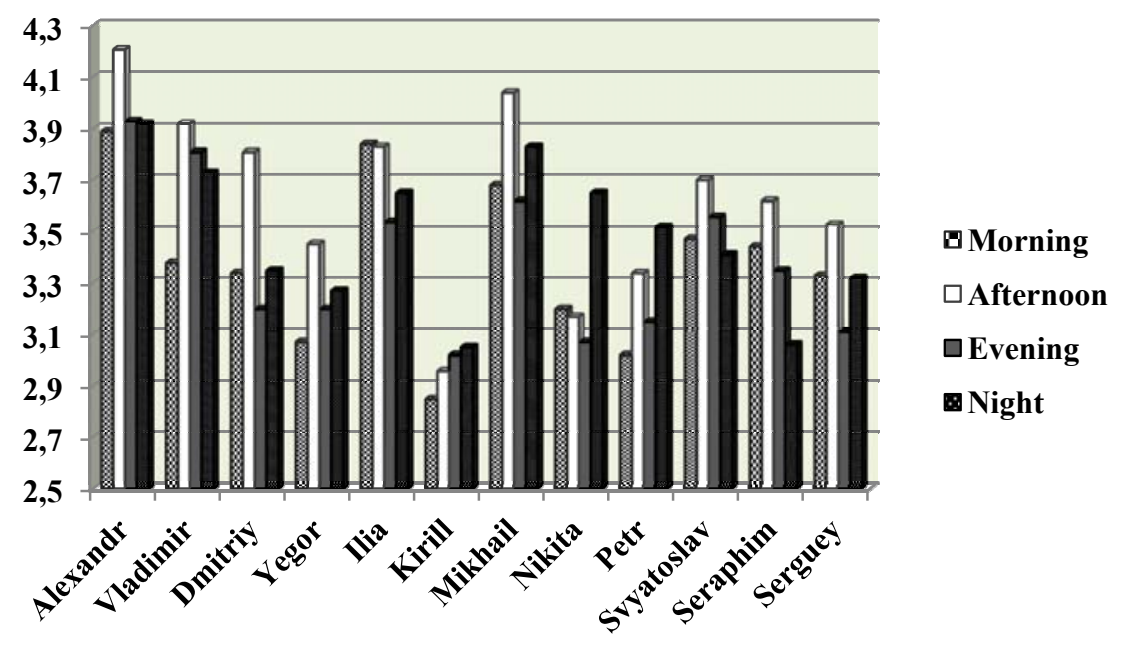

Figure 1. Changes of values of the index Good depending on the time of the day, scores. 


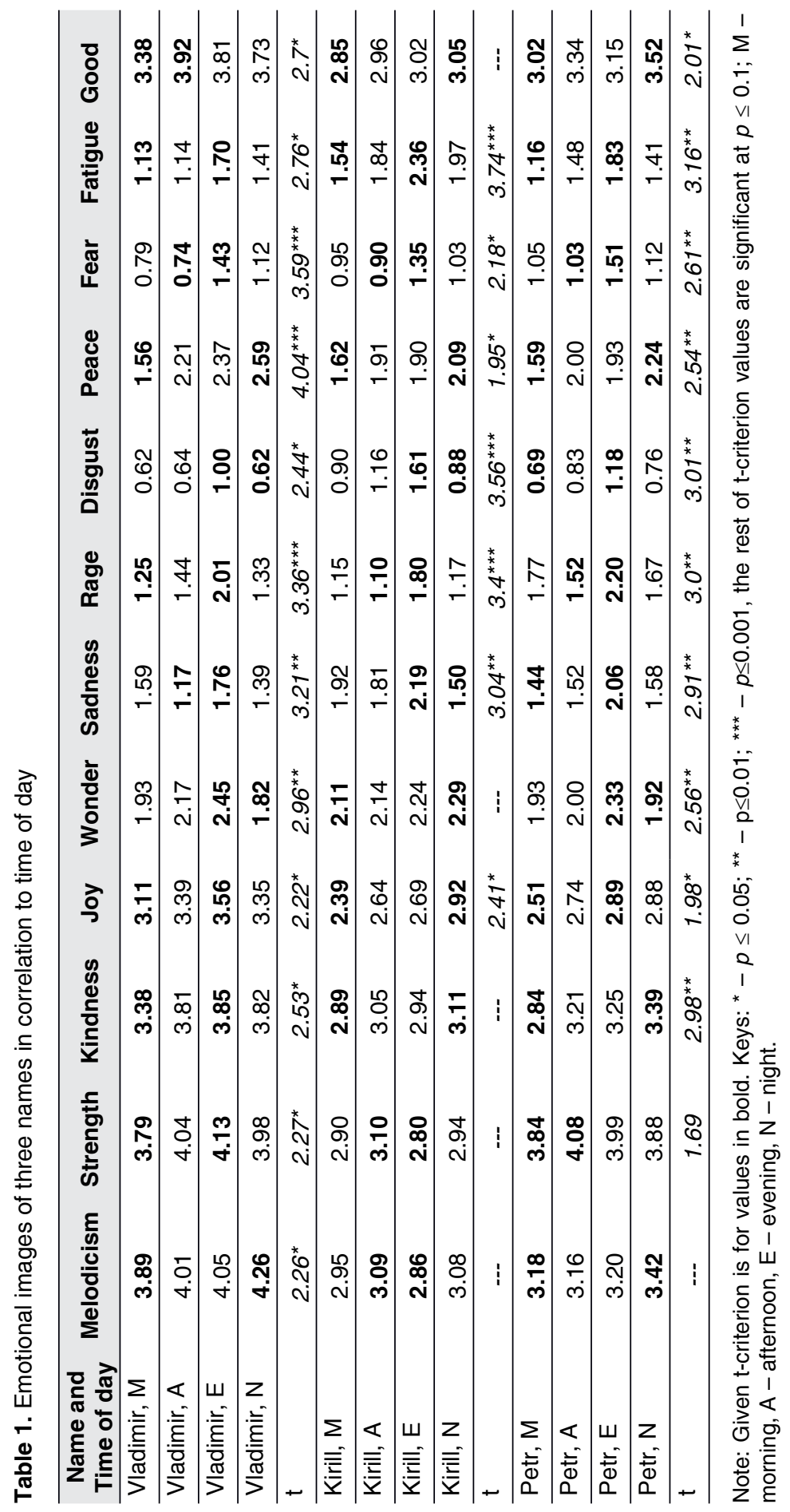


Table 1 shows the values of emotional indices in correlation with the time of the day for three names that are different in the form, phonetic structure and frequency of use. Evidently, there are significant and valid differences for most of the studied indices.

Figure 2 illustrates the changes of values of the studied indices for the vowel $\mathrm{y}[\mathrm{u}]$ depending on time of day, $p \leq 0.05 \div 0.001$.

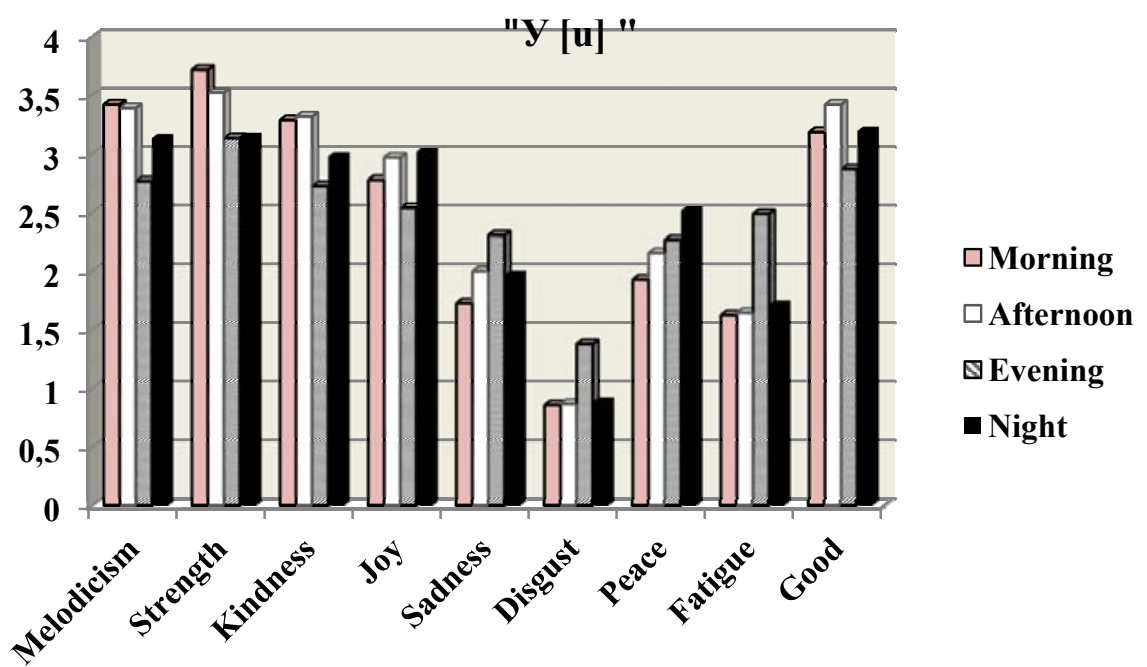

Figure 2. Significant and valid changes of values of the emotional image of the vowel $\mathrm{Y}[\mathrm{u}]$ vowel, scores

In the unfavorable family and social conditions, the low values of an image of the name can possibly put an impact on the personality of its bearer and be transmitted onto their self-esteem and well-being. It is no coincidence that different nations have the tradition of taking a new name in a critical situation. For instance, the famous writer Slavomir Mrozhek, after having an apoplectic attack at the age of 72, saw a mystical dream about his new name Valtasar. Having taken the new name Valtasar, he was able to recover from illness and continue his writing [6].

Grouping all the data for the days of the quiet GMF and the disturbed GMF and its further processing brought the following results - see Table 2. 
Table 2. Values for names and vowels on the days of disturbed GMF (D) and quiet GMF $(\mathrm{Q})$, scores

\begin{tabular}{lcccccccccc}
\hline Names & $\begin{array}{c}\text { Melodi- } \\
\text { cism }\end{array}$ & Joy & $\begin{array}{c}\text { Sad- } \\
\text { ness }\end{array}$ & Disgust & Fatigue & Good & $\mathbf{n}$ & $\begin{array}{c}\text { Vow- } \\
\text { els }\end{array}$ & Good & $\mathbf{n}$ \\
\hline $\mathbf{Q}$ & 3.42 & 3.09 & 1.70 & 0.80 & 1.53 & 3.40 & 969 & $\mathbf{Q}$ & $\mathbf{3 . 2 2}$ & 483 \\
\hline $\mathbf{D}$ & 3.52 & 3.24 & 1.83 & 0.90 & 1.63 & 3.51 & 660 & $\mathbf{D}$ & $\mathbf{3 . 3 8}$ & 330 \\
\hline$p \leq$ & 0.1 & 0.025 & 0.05 & 0.1 & 0.1 & 0.05 & & $p \leq$ & 0.1 & \\
\hline
\end{tabular}

As one can see, on the days of the disturbed GMF values of both positive and negative indices grow, which makes an ambivalent image of the name.

Table 3 represents the results of grouping the values of the studied indices for all the names by the lunar phase. No significant differences detected for vowels, but as for the names there are significant differences for five indices at $p \leq 0.1 \div 0.001$. The values of the indices Kindness, Wonder, Sadness, Rage are decreasing at full moon compared to the new moon, while the value of the index Strength is increasing.

Table 3. Indices of the images of the names at full moon and the new moon, scores

\begin{tabular}{lcccccc}
\hline Lunar phases & Strength & Kindness & Wonder & Sadness & Rage & $\mathbf{N}$ \\
\hline Full Moon & 3.54 & $\mathbf{3 . 4 4}$ & $\mathbf{2 . 3 7}$ & $\mathbf{1 . 5 8}$ & $\mathbf{1 . 2 5}$ & $\mathbf{5 5 2}$ \\
\hline New Moon & 3.46 & $\mathbf{3 . 5 4}$ & $\mathbf{2 . 6 4}$ & $\mathbf{1 . 8 8}$ & $\mathbf{1 . 4 7}$ & $\mathbf{5 5 2}$ \\
\hline$p \leq$ & 0.1 & 0.1 & 0.001 & 0.001 & 0.025 & \\
\hline
\end{tabular}

The correlation analysis was performed for the averaged values for all the names and the vowels for 12 experimental days of the period from 1 February to $5 \mathrm{April}$; for all the data of this period for each name and each vowel; for all the data for 23 experimental days for the whole period of 1 February - 7 June for several respondents. The results are shown in Tables 4, 5 and Figures 3, 4.

Multiple correlations were detected between the studied indices and parameters of environmental surrounding at $p \leq 0.05 \div 0.001$. Most numerous and significant correlations belong to the indice of daylight duration. The highest number of correlations and the highest level of significance were registered at the analysis of individual data. Apparently, the psychophysiological characteristics of a person, including sensitivity to certain environmental parameters, manifest themselves in the variations of reaction to the studied sounds and names. It is reasonable to suppose that a personal name, as an audial signal and the stimulus of many years and of high importance, puts an impact on auditory 
sensitivity of a person, which consequently demonstrates itself at estimating sounds, words and names.

Table 4. Results of the correlation analysis for the averaged emotional images of each name

\begin{tabular}{lcrrrrrr}
\hline \multirow{2}{*}{$\begin{array}{l}\text { Weather } \\
\text { Conditions }\end{array}$} & \multicolumn{6}{c}{ Averaged values of emotional image of men names } \\
\cline { 2 - 8 } & $\begin{array}{c}\text { Melodi- } \\
\text { cism }\end{array}$ & Kindness & Wonder & Sadness & Rage & Disgust & \multicolumn{1}{c}{ Fear } \\
\hline Pressure & 0.139 & -0.203 & $\mathbf{0 . 5 0 6}$ & 0.354 & 0.116 & 0.180 & $\mathbf{0 . 5 9 5 ^ { * }}$ \\
\hline Humidity & -0.341 & 0.241 & -0.478 & $-\mathbf{0 . 6 0 0 ^ { * }}$ & -0.083 & 0.156 & -0.147 \\
\hline Precipitation & 0.277 & -0.136 & $-\mathbf{0 . 5 7 1 ^ { * }}$ & -0.163 & -0.209 & -0.241 & -0.402 \\
\hline DD & 0.167 & $-\mathbf{0 . 4 6 9}$ & 0.140 & 0.255 & -0.464 & $-\mathbf{0 . 5 5 4 ^ { * }}$ & -0.312 \\
\hline Dst & $-\mathbf{0 . 6 1 9 ^ { * }}$ & $\mathbf{0 . 4 7 2}$ & 0.061 & -0.245 & 0.070 & -0.178 & -0.276 \\
\hline W & -0.243 & 0.086 & -0.041 & -0.045 & -0.484 & -0.457 & $-\mathbf{0 . 6 2 0 ^ { * }}$ \\
\hline G & -0.050 & -0.188 & $-\mathbf{0 . 7 2 2 ^ { * * }}$ & -0.435 & -0.329 & 0.012 & -0.174 \\
\hline
\end{tabular}

Key: ${ }^{*}-p \leq 0.05 ;{ }^{* *}-p \leq 0.01 ;{ }^{* *}-p \leq 0.001$.

\section{CONCLUSION}

As a result of a long-term experiment with a constant group of respondents, the variability of values of the images of vowels and personal names was revealed. Significant and valid changes were detected in relation with the time of the day, with comparing the days of quiet and disturbed geomagnetic field and in dependence of the lunar phase- the full moon or the new moon. The correlation analysis showed valid correlations between most of the studied indices and weather conditions, both local and global.

Evidently, the shift value phenomenon is based on the influence of the combination of environmental conditions onto the psychophysiological state of the person and onto the perception of certain sounds and words, their consonancy or dissonancy. There is also a certain impact from the inherent biorhythms of the person, especially from the infra-low frequencies of their own biomagnetic field [4]. Eventually, the combinations of certain environmental conditions during prolonged periods of time can result in intensifying the positive image of some words and personal names and in changing the frequency of use of some words in speech. In its turn, it is manifested in the evolution of the language, naming trends, etc. This is why choosing a personal name should be based on knowing the name's semantics, on its melodicism, color and emotional images. 
The results of the study should be interesting for medical anthropology, psychosemantics and psychotherapy professionals.

Table 5. Results of correlation analysis of average values for all vowels

\begin{tabular}{lccccc}
\hline \multirow{2}{*}{$\begin{array}{l}\text { Weather } \\
\text { conditions }\end{array}$} & \multicolumn{5}{c}{ Averaged values of emotional image of 6 vowels } \\
\cline { 2 - 6 } & Melodicism & Strength & Kindness & Wonder & Rage \\
\hline Pressure & $\mathbf{0 . 5 7 3 ^ { * }}$ & $\mathbf{0 . 5 2 2}$ & $\mathbf{0 . 5 1 3}$ & 0.247 & 0.150 \\
\hline Humidity & $-\mathbf{0 . 5 5 6}$ & -0.065 & -0.071 & -0.054 & 0.020 \\
\hline Precipitation & -0.372 & -0.383 & -0.087 & $-\mathbf{0 . 7 3 5 ^ { \star \star }}$ & -0.376 \\
\hline DD & 0.173 & -0.296 & 0.102 & -0.246 & $-\mathbf{0 . 5 1 3}$ \\
\hline W & -0.295 & -0.364 & -0.234 & -0.219 & -0.394 \\
\hline G & $-\mathbf{0 . 5 7 8 ^ { * }}$ & -0.400 & -0.232 & $-\mathbf{0 . 5 2 5}$ & -0.428 \\
\hline
\end{tabular}

Key: ${ }^{*}-p \leq 0.05 ;{ }^{* *}-p \leq 0.01$.

\section{Good}
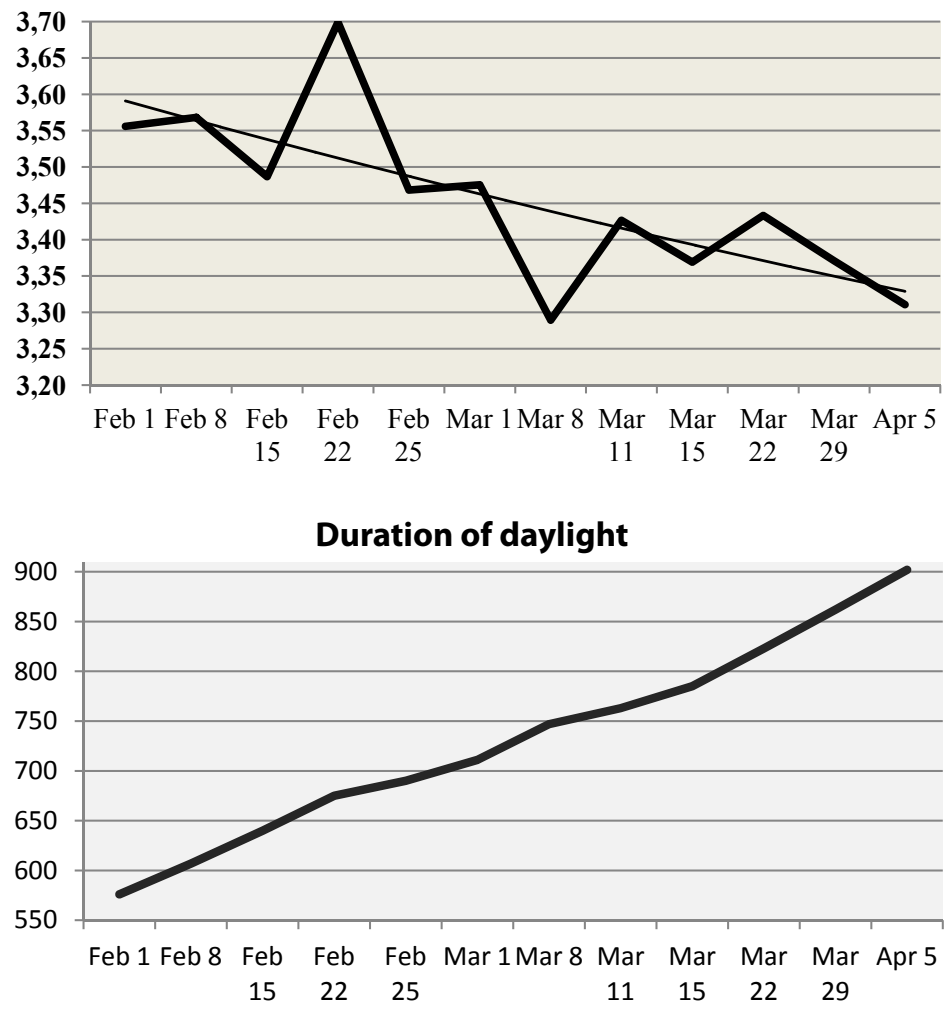

Figure 3. Correlation between changes in the index Good (scores) and the index Duration of Daylight (minutes), averaged for all names; $r=-0.723$. The thin line is a polynomial trend. 


\section{Duration of daylight}
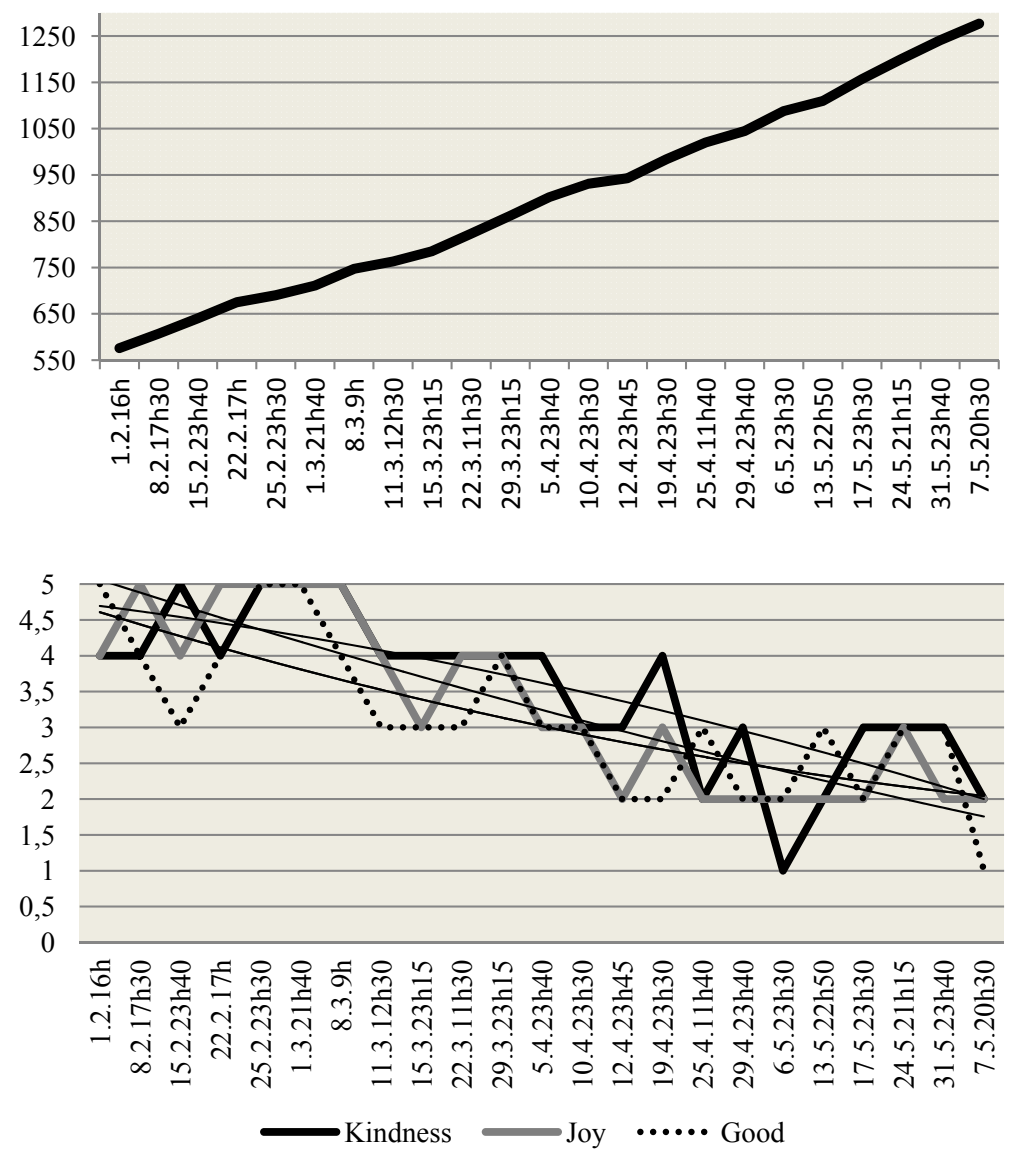

Figure 4. Correlation between the indices Kindness, Joy, Good for the name Seraphim and the index Duration of Daylight for the respondent Ekaterina T., $r=-0.753 ;-0.839$; -0.744 . Thin lines are polynomial trends.

\section{REFERENCES}

1. Bragina N. N., Dobrokhotova T. A. (1977). Functional asymmetry and psychopathology of focal brain lesion. Moscow, Meditsina, 359.

2. Volchek O. D. (2011). Sounds, Words, Names. Spb, Knizhniy Dom, 294.

3. T. M. Rogozhnikova and others. Associative portrait gallery. General editorship by T. M.Rogozhnikova, Ufa, UGATU, 448.

4. Yegorov V. V. (2010). Low frequency spectra of human electric field. Nanotechnologies and health care, T.P, 3 (4), 44-47.

5. Zhuravlev A. P. (1974). Phonetical meaning. Leningrad, LGU Publishing, 166. 
6. Mrozhek Slavomir. Varietal (2008). Autobiography. Translated by Vadim Klimovskiy. Foreign Litearture, 6, 159-245.

7. Nasledov A. D. (2006). Mathematic methods in psychological research. Analysis and interpretation of data. Spb, Rech, $392 \mathrm{p}$.

8. Florenskiy P. A. (1993). Names. The archives of the priest Pavel Florenskiy. Kostroma, Kupina, 320 p.

Address for correspondence:

Olga D. Volchek

volchekod@mail.ru 